\title{
"A Novel Control Strategy Based on Predictive Control for a Bidirectional Interleaved Three-
} Phase Converter"

CONTROLO 13th APCA International Conference on Control and Soft Computing, pp.73-78, Azores, Portugal, June 2018.

DOI: $10.1109 /$ CONTROLO.2018.8514262

ISBN: 978-1-5386-5346-3

ISSN: $2472-8489$

This material is posted here with permission of the IEEE. Such permission of the IEEE does not in any way imply IEEE endorsement of any of Group of Energy and Power Electronics, University of Minho, products or services. Internal or personal use of this material is permitted. However, permission to reprint/republish this material for advertising or promotional purposes or for creating new collective works for resale or redistribution must be obtained from the IEEE by writing to pubs-permissions@ieee.org. By choosing to view this document, you agree to all provisions of the copyright laws protecting it. 


\title{
A Novel Control Strategy Based on Predictive Control for a Bidirectional Interleaved Three-Phase Converter
}

\author{
Vítor Monteiro, Tiago J. C. Sousa, Júlio S. Martins, J. C. Aparício Fernandes, João L. Afonso \\ ALGORITMI Research Centre - University of Minho \\ Guimarães - Portugal \\ \{vmonteiro | tsousa $\mid$ jmartins $\mid$ aparicio $\mid$ jla\}@dei.uminho.pt
}

\begin{abstract}
An experimental confirmation of predictive control applied to a bidirectional interleaved three-phase (BIT) converter is presented. The BIT converter is a powerful solution for numerous applications, mainly, renewables interface, motor drivers, active rectifiers, and active power filters. However, a precise and robust digital control strategy is required, maintaining a low computational effort. In this paper, a predictive control based on continuous control set is proposed as a new control scheme for the BIT converter, permitting the control of the ac side current with fixed switching frequency and with a faster response. The predictive control scheme applied to the BIT converter is defined along the paper, evidencing in detail the digital employment aspects according to the discrete-time model of the BIT converter. An explicit experimental validation under realistic operating conditions is presented using a developed laboratorial prototype, highlighting the convenience of the control applied to the BIT converter.
\end{abstract}

Keywords-Predictive Control; Bidirectional Interleaved Three-Phase Converter; Current Control; Power Quality.

\section{INTRODUCTION}

Nowadays, the importance of power quality contributes to the emergence of new topologies of active rectifiers as a main alternative of passive rectifiers based on diode and multi-pulse rectifiers [1][2]. Therefore, using active rectifiers, a sinusoidal grid current with low total harmonic distortion, a high power factor, and a controllable output voltage is achieved [3][4], both for single- and three-phase systems [5]. The conventional solutions are created by a front-end ac-dc diode rectifier followed by a back-end dc-dc switched converter. For the back-end dc-dc converter, the traditional boost, buck, buck-boost, or flyback converters can be employed [6][7]. An assessment about the crucial active rectifiers, highlighting the key features of the different topologies, is presented in [8] and [9]. In order to avoid the necessity of two power stages, bridgeless converters are also applied as active rectifiers, allowing the same benefits of controlled grid current, total power factor and output voltage [10]. Extended reviews of bridgeless active rectifiers based on symmetrical and asymmetrical schemes are presented in [11], [12], and [13]. Besides the bridgeless converters, interleaved converters are also a pertinent set of active rectifiers [14]. In the similar background of power quality improvement, new topologies of grid-tied inverters are emerging as an alternative to the conventional full-bridge and neutral-point clamped inverters, mainly as a support for renewables interface. Therefore, in a smart grid perspective, joining in a single converter the characteristics of an active rectifier and a grid-tied inverter, represents a central asset for several applications including bidirectional electric vehicle battery chargers and active power filters with renewables interface [15][16]. In this context, a bidirectional interleaved three-phase (BIT) converter with a novel control strategy is presented in this paper.

In terms of control, the nonlinear hysteresis and the linear sinusoidal pulse-width modulation (SPWM) are the most conservative current control schemes [17][18]. Also fuzzy-controllers, sliding mode, periodic sampling, or feedforward strategies can be applied for current control schemes [19]. Besides such arrangements, with the progress of microcontrollers over the last decades, predictive arrangements appear as more intuitive strategies for power electronics converters. Moreover, with predictive controllers the nonlinearities of the converter can be involved in the control scheme (for instance, the passive filters values), representing a significant gain comparing to other schemes [20]. Dead-beat, hysteresis-based, generalized predictive control, trajectory-based and predictive control with continuous control set or with finite control set are the main predictive schemes applied in power electronics converters [20]. Predictive control has been useful for a varied range of applications due to its flexibility, including voltage and current source converters [21], shunt active power filters [22], and uninterruptible power supplies [23].

Aiming to establish a grid current control scheme, any of the aforementioned strategies can be applied. However, in the scope of this paper, the BIT converter is controlled by a scheme based on a continuous control set predictive control, representing one of the main contributions of this paper. It was selected this strategy, since it was never applied as a control scheme for a BIT converter and due to the simplicity of digital implementation, flexibility to accommodate the nonlinearities of the converter, and fast response for a wide range of operating power. Therefore, the state of the BIT converter is defined according to the output of a modulator, maintaining a fixed switching frequency with the inherent advantages for the passive filters design. Taking into account the scope of this paper, the main contributions are: novel control strategy based 


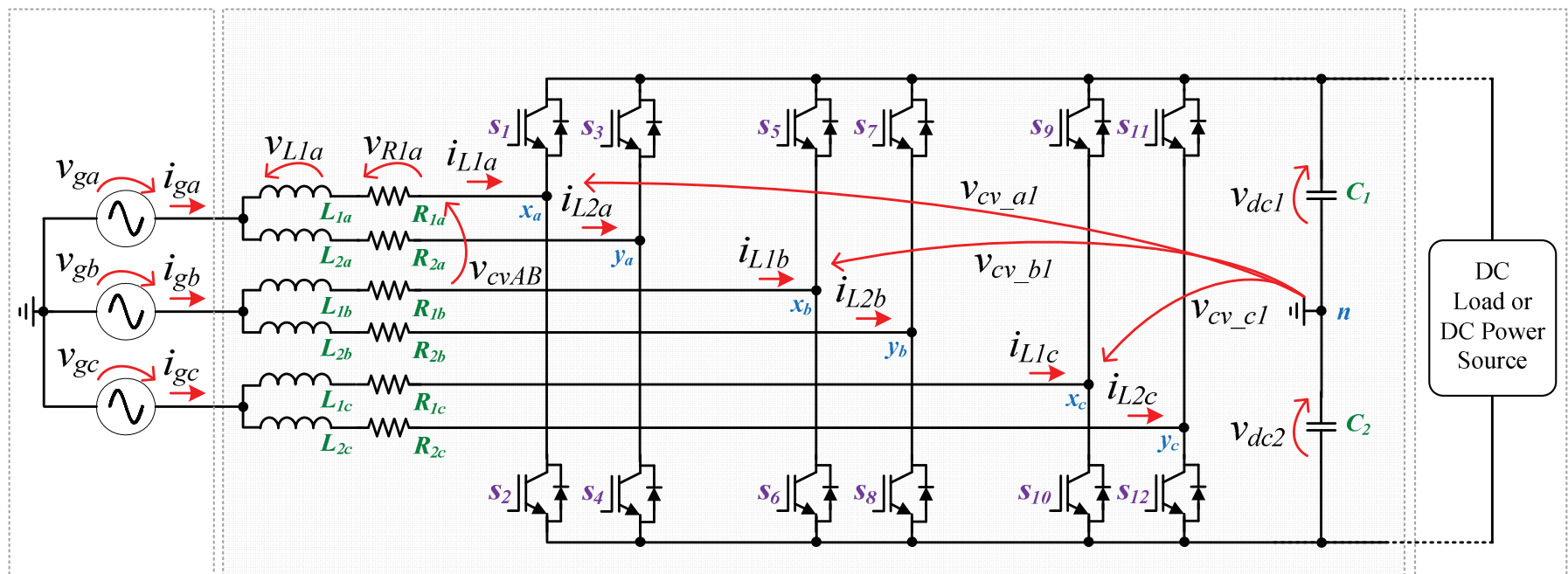

Fig. 1. Bidirectional interleaved three-phase (BIT) converter connected to the power grid for the operation as active rectifier or as grid-tie inverter.

on predictive control for a BIT converter; description of the predictive control applied to the BIT converter in detail and as a comprehensive method; experimental validation of the predictive control applied to the BIT converter, i.e., operating with sinusoidal grid currents, power factor, and dc-link voltage.

The rest of this paper is structured as follows. The detailed description of the BIT converter is presented in section II, the proposed predictive control scheme for the BIT converter is presented in section III, the experimental validation is presented in section IV, and the main conclusions are presented in section $\mathrm{V}$.

\section{DESCRIPTION OF THE BIDIRECTIONAL INTERLEAVED THREE-PHASE (BIT) CONVERTER}

The structure of the BIT converter is shown in Fig. 1, which is composed by a single-phase full-bridge boost-type voltage-source converter for each phase, i.e., by six IGBTs legs, two for each phase, and each leg has a coupling inductor to interface the power grid. The dc-link is formed by two capacitors with the middle point connected to the neutral of the power grid, allowing the operation of the BIT converter in four-wire systems (useful, for instance, for three-phase four-wire active power filters). With this topology, the ripple of the grid current is reduced by a factor of 2 (corresponding to the number of legs of each phase), and the resultant switching frequency is increased also by a factor of 2. This is especially advantageous for a well-defined grid current ripple and frequency, since the required switching frequency can be reduced when compared with the conventional solutions. Moreover, the current rating of each IGBT is reduced by a factor of 2, as well as the switching and conduction losses when compared to the conventional solutions.

During the operation as an active rectifier (receiving energy from the power grid) or as a grid-tie inverter (delivering energy to the power grid), the BIT converter operates with sinusoidal grid currents and the phase angle between the current and the voltage of each phase can be individually controlled in order to adjust the total power factor. Using the phase $a$ as example, the voltage $v_{c v a l}$ (between points $x_{a}$ and $n$ ) and the voltage $v_{c v b l}$ (between points $y_{a}$ and $n$ ) are positive $\left(+v_{d c l}+v_{d c 2}\right)$ or negative $\left(-v_{d c l}-v_{d c 2}\right)$ independently of the power grid voltage half-cycle. However, the summing of these voltages $\left(v_{c v_{a} a l}\right.$ with $\left.v_{c v_{-} b l}\right)$, i.e., a phase-to-phase voltage, assumes the voltage levels $-v_{d c}, 0$, and $+v_{d c}$, where $v_{d c}$ is the summing of $v_{d c l}$ with $v_{d c 2}$, resulting in a three-level voltage. Considering this phase-to-phase voltage, during the period when $v_{g a}>v_{g b}$, the phase-to-phase voltage assumes the levels of 0 and $+v_{d c}$, and when $v_{g a}<v_{g b}$, the phase-to-phase voltage assumes the levels of 0 and $-v_{d c}$.

\section{Predictive Control Scheme}

A predictive is used to control the different operating conditions of the BIT converter, i.e., to regulate the grid current as a function of its reference. The control scheme guarantees that the three grid currents $\left(i_{g a}, i_{g b}\right.$, and $\left.i_{g c}\right)$ are sinusoidal, regardless of the harmonic distortion of the power grid voltages $\left(v_{g a}, v_{g b}\right.$, and $\left.v_{g c}\right)$, are balanced through the three phases, and the phase angle between each grid current and the respective phase voltage can be controlled, allowing the operation with adjustable power factor (capacitive or inductive). Therefore, the BIT converter can operate in four quadrants, representing a powerful solution for several applications, mainly, renewables interface, bidirectional electric vehicle battery chargers, motor drivers, active rectifiers, and active power filters.

Analyzing the BIT converter from the power grid, it can operate in two distinct modes: operation similar to a balanced and linear load with adjustable operating power and power factor; operation similar to an energy source injecting energy to the power grid. In both modes, besides the active power control, the reactive power can also be controlled. Therefore, the instantaneous values of the grid currents $\left(i_{g\{a, b, c\}}\right)$ are a function of the power grid voltages $\left(v_{g\{a, b, c\}}\right)$ :

$$
i_{g\{a, b, c\}}(t)=f\left(v_{g\{a, b, c\}}(t)\right),
$$

where $a, b$ and $c$ are the power grid phases. For the BIT converter operation in the four quadrants, the function should be established in terms of a signal in phase with the power grid voltage (in order to control the active power) and another one with a phase-shift of 90 degrees (in order to control the reactive power), resulting in a control equation of: 


$$
\begin{gathered}
i_{g\{a, b, c\}}(t)=f_{P\{a, b, c\}}(t) v_{g P\{a, b, c\}}(t)+ \\
f_{Q\{a, b, c\}}(t) v_{g Q\{a, b, c\}}(t),
\end{gathered}
$$

where both $f_{P\{a, b, c\}}(t)$ and $f_{Q\{a, b, c\}}(t)$ terms are controlled in terms of amplitude, aiming to adjust the operating active and reactive power. The instantaneous values of the signals $v_{g P\{a, b, c\}}(t)$ and $v_{g Q\{a, b, c\}}(t)$ are obtained from a phase-looked loop (PLL) algorithm, where the power grid voltages $v_{g\{a, b, c\}}(t)$ are the input signals of such PLL [24]. The term $f_{P\{a, b, c\}}(t)$ is established to adjust the operating active power $\left(P_{B I T}(t)\right)$ and the power necessary to regulate the dc-link voltage $\left(P_{D C}(t)\right)$, according to:

$$
\begin{aligned}
& f_{P\{a, b, c\}}(t)=\frac{P_{B I T a}(\mathrm{t}) P_{B I T b}(\mathrm{t})}{V_{G a}{ }^{2}(\mathrm{t}) V_{G b}{ }^{2}(\mathrm{t}) V_{G c}{ }^{2}(\mathrm{t})}+\frac{P_{D C}(t)}{3 V_{G a}{ }^{2}(t)} \\
& +\frac{P_{B I T a}(\mathrm{t}) P_{B I T b}(\mathrm{t})}{V_{G a}{ }^{2}(\mathrm{t}) V_{G b}{ }^{2}(\mathrm{t}) V_{G c}{ }^{2}(\mathrm{t})}+\frac{P_{D C}(t)}{3 V_{G b}{ }^{2}(t)} \\
& +\frac{P_{B I T b}(\mathrm{t}) P_{B I T C}(\mathrm{t})}{{V_{G a}}^{2}(\mathrm{t}) V_{G b}{ }^{2}(\mathrm{t}){V_{G C}}^{2}(\mathrm{t})}+\frac{P_{D C}(t)}{3{V_{G c}}^{2}(t)}
\end{aligned}
$$

and the term $f_{Q\{a, b, c\}}(t)$ is established to adjust the operating reactive power $\left(Q_{B I T}(t)\right)$, according to:

$$
\begin{aligned}
& f_{Q\{a, b, c\}}(t)=\frac{Q_{B I T a}(\mathrm{t}) Q_{B I T b}(\mathrm{t})}{V_{G a}{ }^{2}(\mathrm{t}) V_{G b}{ }^{2}(\mathrm{t}) V_{G c}{ }^{2}(\mathrm{t})} \\
& +\frac{Q_{B I T a}(\mathrm{t}) Q_{B I T b}(\mathrm{t})}{V_{G a}{ }^{2}(\mathrm{t}) V_{G b}{ }^{2}(\mathrm{t}) V_{G c}{ }^{2}(\mathrm{t})} \\
& +\frac{Q_{B I T b}(\mathrm{t}) Q_{B I T C}(\mathrm{t})}{{V_{G a}}^{2}(\mathrm{t}){V_{G b}}^{2}(\mathrm{t}){V_{G C}}^{2}(\mathrm{t})} \text {. }
\end{aligned}
$$

where $V_{G\{a, b, c\}}$ are the rms values of each phase voltage. The currents established in (1) are the reference currents for the BIT converter. Therefore, a precise and robust digital control strategy is required, maintaining a low computational effort. In the scope of this paper, a predictive control based on continuous control set is proposed as a new control scheme for the BIT converter, controlling the grid current with fixed switching frequency.

In order to simplify the current control analysis, Fig. 2 shows in detail the phase $a$ of the BIT converter connected to the power grid (leg formed by the inductances $L_{1}$ and $L_{2}$ and by the IGBTs $s_{1}, s_{2}, s_{3}$, and $s_{4}$ ). For the leg formed by $s_{1}$ and $s_{2}$, the voltages are related according to:

$$
v_{g a}(\mathrm{t})-v_{L 1 a}(t)-v_{R 1 a}(t)-v_{c v_{-} a 1}(t)=0,
$$

where $v_{c v_{a} a l}(\mathrm{t})$ is the voltage established by the converter for the first leg of phase $a$ in accordance with the dc-link voltage (cf. Fig. 1), $v_{L I}(t)$ is the inductance voltage, and $v_{R I}(t)$ the inductor internal resistance voltage drop. Substituting the inductance voltage, results in:

$$
v_{g a}(\mathrm{t})-L_{1 a} \frac{d i_{L 1 a}(t)}{d t}-v_{R 1 a}(t)-v_{c v_{-} a 1}(t)=0 .
$$

Regarding a digital implementation, the grid voltage variation

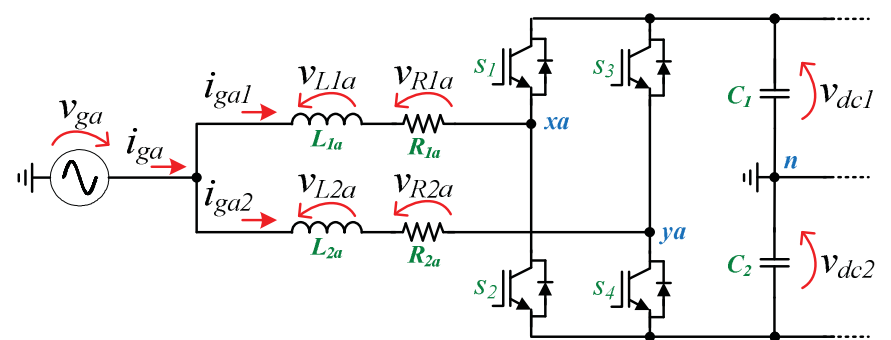

Fig. 2. Detail of phase $a$ of the BIT converter.

during a sampling period $[k-1, k]$ can be determined by:

$$
\overline{v_{g a}}[k]=\frac{3}{2} v_{g a}[k]-\frac{1}{2} v_{g a}[k-1] .
$$

As example, this strategy was adopted in [25] for an improved predictive strategy. The same method can be applied to determine the variation of the resistance voltage. On the other hand, applying the forward Euler method to discretize the inductance voltage during a sampling period $[k, k+1]$ with a sampling period of $T_{s}$, results in:

$$
v_{L 1}[k]=L_{1 a} \frac{i_{g a 1}[k+1]-i_{g a 1}[k]}{T_{S}} .
$$

Therefore, the final digital control law, i.e., the voltage established by the BIT converter in the first leg of phase $a$ (leg formed by the IGBTs $s_{1}$ and $s_{2}$ ), is established as:

$$
\begin{gathered}
v_{c v_{a 1}}[k]=\frac{3}{2} v_{g a}[k]-\frac{1}{2} v_{g a}[k-1]-, \\
-L_{1 a} \frac{i_{g a 1}[k+1]-i_{g a 1}[k]}{T_{S}} \\
\frac{3}{2} R_{1 a} i_{R 1 a}[k]-\frac{1}{2} R_{1 a} i_{R 1 a}[k-1] .
\end{gathered}
$$

Analyzing this equation and excepting the value of $i_{\text {gal }}[k+1]$, the other values are obtained from the measurements in the instant $[k]$, i.e., at the beginning of the sampling period. However, in order to control the grid current during each sampling period $[k, k+1]$, it is necessary to know the grid current future value of $i_{L l a}[k+1]$. This value in $[k+1]$ represents the value that the current should have in order to minimize the current error, i.e., this is the value used as reference $\left(i_{L 1 a} *[k+1]\right)$ taking into account the operating power of the BIT converter. The current error is minimized when the mean value of the grid current during the sampling interval $[k, k+1]$ reaches the constant value of the reference current predicted for such period. In this context, discretizing the grid current reference for the phase $a$ established in (1), results in:

$$
i_{g a}[k]=f_{P a}[\mathrm{k}] v_{g P a}[k]+f_{Q a}[k] v_{g Q a}[k] .
$$

Taking into consideration that the grid current in phase $a$ is divided in two currents with the same amplitude and frequency (each one for each leg of such phase), the reference for the first leg is obtained according to: 


$$
i_{g a 1}[k]=\frac{i_{g a}[k]}{2} .
$$

Using (11), the predicted grid current $\left(i_{g a l}\right)$ for the instant $[k+1]$ can be obtained using the past and present values of $i_{g a l}$ (determined in previous sampling periods) and using a second-order extrapolation method established by:

$$
i_{g a 1}[k+1]=3 i_{g a 1}[k]-3 i_{g a 1}[k-1]+i_{g a 1}[k-2] .
$$

This extrapolation method, applied to predictive strategies of power electronics converters [26], allows to obtain the value of $i_{g a l}[k+1]$ to be used in (9). Therefore, the grid current is measured in $[k]$ and during the sampling period $[k, k+1]$ it is forced to follow the predicted reference for $[k+1]$. The same reasoning is directly applied for the next sampling period $([k+1, k+2])$ and for the other legs of phases $b$ and $c$. Using this strategy, a prediction horizon of one is considered, but as presented in [27][28], longer prediction horizons can be considered. Section IV presents the experimental validation where the sampling and switching frequencies are introduced.

For the correct operation of the BIT converter, the introduction of a dead-time in each leg is required. However, the introduction of such dead-time causes a distortion in the voltage established by the BIT converter in each leg, and, consequently, in the obtained grid currents $\left(i_{g a}, i_{g b}\right.$, and $\left.i_{g c}\right)$. Therefore, an additional control strategy is added to the predictive control aiming to compensate the introduction of the dead-time. Thus, a digital value $(\Delta v)$, determined according to:

$$
\Delta v=\frac{2 \Delta t}{T_{s}} v_{d c} \operatorname{sgn}\left(i_{g}\right),
$$

where $\Delta t$ is the dead-time value and $T s$ the period of the carrier. The compensation value $\Delta v$ is added to the reference voltage throughout the positive half-cycle and subtracted throughout the negative half-cycle. Therefore, the final reference voltage is obtained according to:

$$
v_{c v_{a 1}}{ }^{*}[k]=v_{c v_{a 1}}[k]+\Delta v \text {. }
$$

The value of the voltage established by the BIT converter $\left(v_{\text {cval }}{ }^{*}[k]\right)$ is updated during each sampling period and compared with a triangular carrier (center aligned $20 \mathrm{kHz}$ signal) in a pulse-width modulation (PWM) structure. Since for each phase two legs of IGBTs are used, and the BIT converter operates in an interleaved mode, two triangular carriers shifted by 180 degrees are used. Therefore, the resulting current in the power grid has a resultant frequency of $40 \mathrm{kHz}$, i.e., the double of the switching frequency.

\section{EXPERIMENTAL VALIDATION}

The laboratorial prototype of the BIT converter used for the experimental validation is presented in Fig. 3. It is composed by three essential parts: acquisition and signal conditioning; digital controller; command circuit and BIT converter. The main specifications of this laboratorial prototype are presented

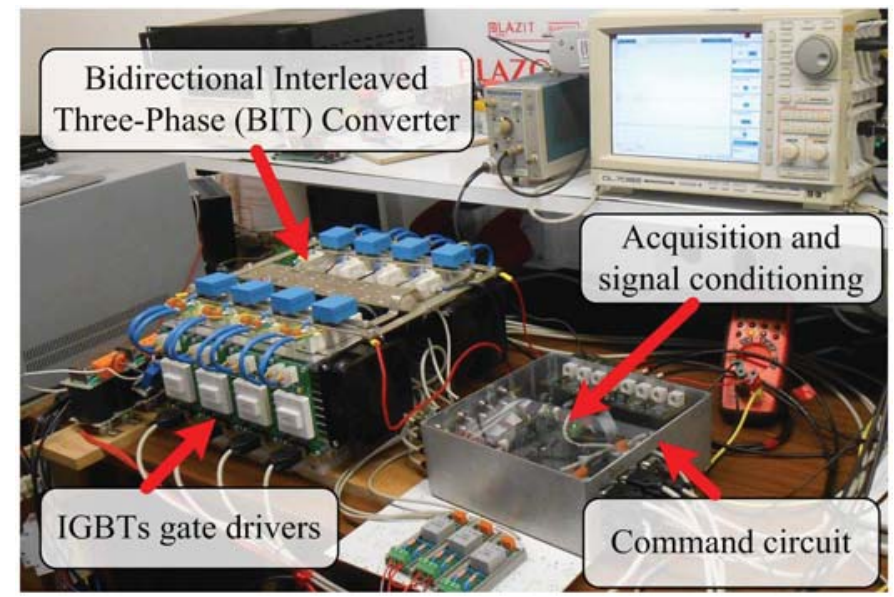

Fig. 3. Laboratorial prototype used for the experimental validation of the BIT converter.

in Table I. The results were obtained with a Yokogawa digital oscilloscope and a Fluke power quality analyzer with non-differential voltage probes.

TABLE I

SPECIFICATIONS OF THE BIT CONVERTER

\begin{tabular}{cc}
\hline \hline Parameters & Value \\
\hline Single-Phase Voltage & $230 \mathrm{~V}$ \\
Grid Current Total Harmonic Distortion & $<3 \%$ \\
Maximum Power & $10 \mathrm{kVA}$ \\
Grid Side Inductors $\mathrm{L}_{\{1, \ldots, 6\}}$ & $2 \mathrm{mH}$ \\
Dc-link Capacitors $\mathrm{C}_{\{1,2\}}$ & $2.6 \mathrm{mF}$ \\
Switching and Sampling Frequency & $20 \mathrm{kHz}$ \\
\hline \hline
\end{tabular}

Fig. 4 shows the power grid voltages $\left(v_{g a}, v_{g b}\right.$, and $\left.v_{g c}\right)$ and the grid currents $\left(i_{g a}, i_{g b}\right.$, and $\left.i_{g c}\right)$ during the operation of the BIT converter as an active rectifier with unitary power factor. As it can be observed, due to the aforementioned control strategy based on predictive control, balanced and sinusoidal grid currents are obtained although the harmonic distortion of the power grid voltages $(\mathrm{THD}=4.1 \%)$. Using a FLUKE 435 power quality analyzer, the measured THD and the harmonic content of the grid currents are shown in Fig. 5.

Fig. 6 shows the phase-to-phase voltage $\left(v_{c v A B}\right)$ assumed by the BIT converter, the current in each IGBT leg of phase $a\left(i_{\text {gal }}\right.$ and $\left.i_{g a 2}\right)$, and the dc-link voltage $\left(v_{d c}\right)$. As expected, the phase-to-phase voltage assumes the three values of $-v_{d c}, 0$, and $+v_{d c}$, both currents of phase $a$ are in phase (although the ripples are in phase opposition), and the dc-link voltage $\left(v_{d c}\right)$ is constant. The resultant current in the power grid side, i.e., the grid current $\left(i_{g a}\right)$, is the summing of both currents igal and $i_{g a 2}$. The same is applicable for phases $b$ and $c$.

A detail of both currents in phase $a\left(i_{g a l}\right.$ and $\left.i_{g a 2}\right)$ and the resultant grid current $\left(i_{g a}\right)$ is shown in Fig. 7. In this specific case, when the grid current crosses the zero (where the duty-cycle is almost $50 \%$ ), the ripple of the resultant grid current $\left(i_{g a}\right)$ is almost neglected, representing an important advantage of the BIT converter.

The same variables are shown in Fig. 8, but for a different angle, i.e., showing the amplitude and frequency in the ripple of the resultant current $\left(i_{g a}\right)$. In this case, as the duty-cycle is different from $50 \%$, it is clearly identified that the ripple of the resultant current has the double of the switching frequency, i.e., 


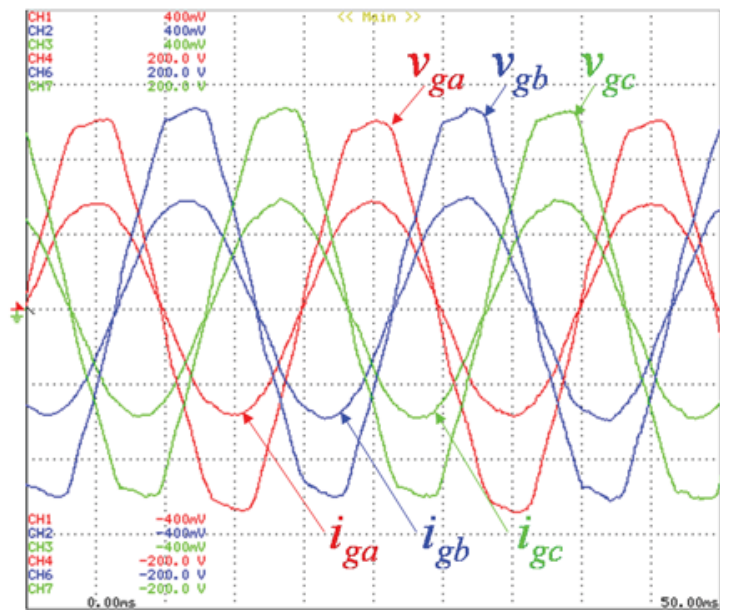

Fig. 4. Experimental results showing a detail of $50 \mathrm{~ms}$ : Power grid voltages $\left(v_{g a}, v_{g b}, v_{g c}\right)$; Grid currents $\left(i_{g a}, i_{g b}, i_{g c}\right)$.

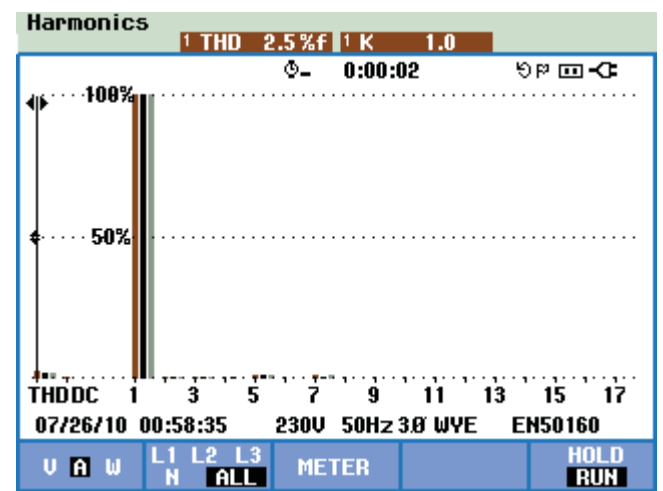

Fig. 5. Experimental results of the THD and harmonic content of the grid currents $\left(i_{g a}, i_{g b}, i_{g c}\right)$.

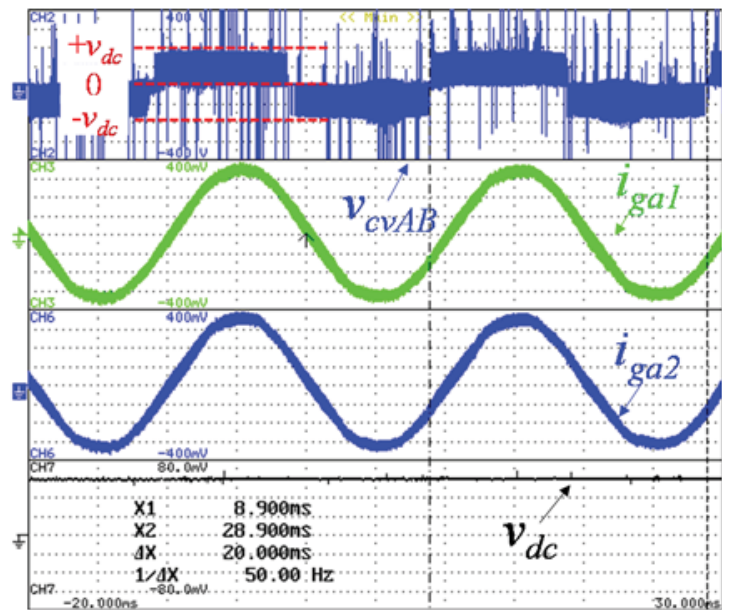

Fig. 6. Experimental results showing a detail of $50 \mathrm{~ms}$ : Phase-to-phase voltage $\left(v_{c v A B}\right)$; Currents in phase $a\left(i_{g a l}, i_{g a}\right)$; Grid current of phase $a\left(i_{g a}\right)$; Dc-link voltage $\left(v_{d c}\right)$.

the frequency presented in the grid currents $\left(i_{g a l}, i_{g a 2}\right)$ ripple. This figure also shows in detail the phase-to-phase voltage, where, in this case, the two voltage levels 0 and $+v_{d c}$ can be identified, since these experimental results were obtained during the positive half-cycle. Fig. 9 shows the power grid voltages $\left(v_{g a}, v_{g b}\right.$, and $\left.v_{g c}\right)$ and the grid currents $\left(i_{g a}, i_{g b}\right.$, and $\left.i_{g c}\right)$ during the operation as an active rectifier with an active power

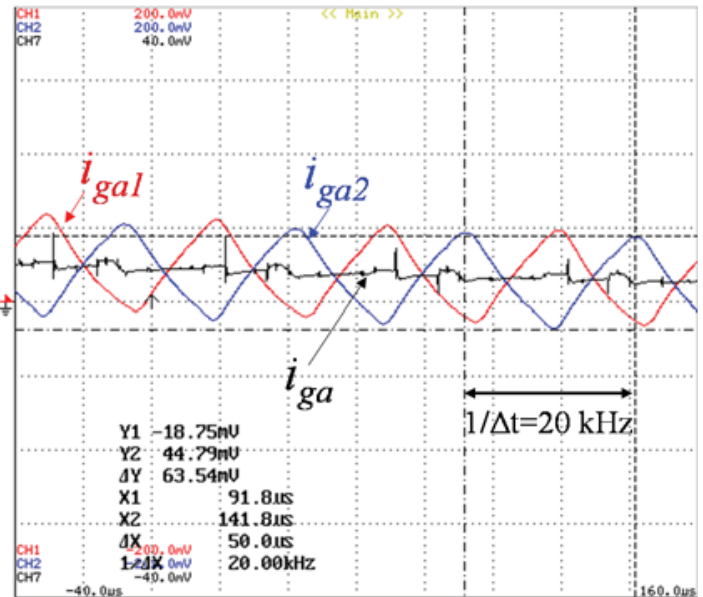

Fig. 7. Experimental results showing in detail of $200 \mu$ s: Currents in phase $a$ $\left(i_{g a l}, i_{g a 2}\right)$; Grid current of phase $a\left(i_{g a}\right)$

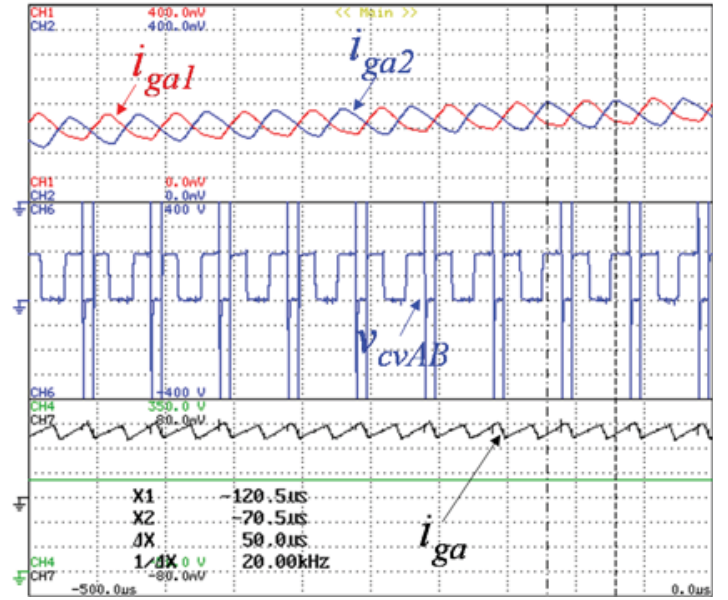

Fig. 8. Experimental results showing a detail of $500 \mu$ s: Currents in phase $a$ $\left(i_{g a l}, i_{g a 2}\right)$; Phase-to-phase voltage $\left(v_{c v A B}\right)$; Grid current of phase $a\left(i_{g a}\right)$.

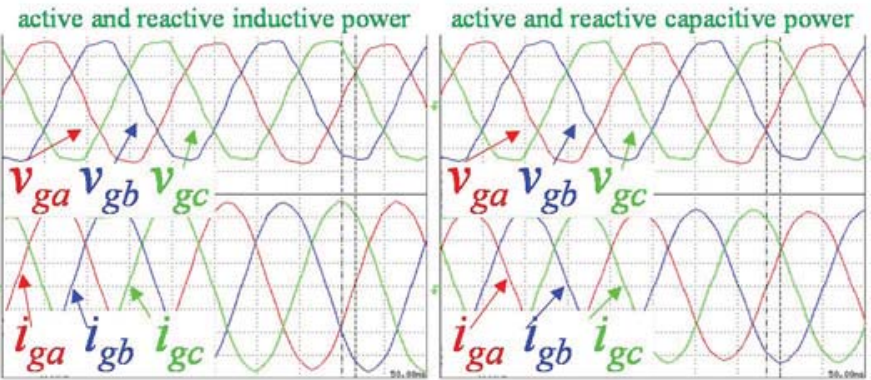

Fig. 9. Experimental results showing a detail of $50 \mathrm{~ms}$ of the power grid voltages $\left(v_{g a}, v_{g b}, v_{g c}\right)$ and grid currents $\left(i_{g a}, i_{g b}, i_{g c}\right)$ during operation with: (a) Active and reactive inductive power; (b) Active and reactive capacitive power.

of $8 \mathrm{~kW}$ and a reactive power of $4 \mathrm{kVAr}$, both inductive (Fig. 9(a)) and capacitive (Fig. 9(b)).

\section{CONCLUSION}

A novel control strategy based on predictive control for a bidirectional interleaved three-phase (BIT) converter is presented. Along the paper is highlighted the importance of the BIT converter for several applications, as well as the good performance of predictive control in terms of precision and robustness, permitting to control the ac side current with fixed 
switching frequency and with a faster response. The control equations of the digital implementation are described in detail and in a comprehensive approach. A laboratorial prototype is described, and obtained experimental results under realistic circumstances of operation corroborate the suitability of the predictive control applied to the BIT converter.

\section{ACKNOWLEDGMENT}

This work has been supported by FCT - Fundação para a Ciência e Tecnologia in the scope of the project: PEstUID/CEC/00319/2013. This work has been supported by COMPETE: POCI-01-0145-FEDER-007043 and FCT Fundação para a Ciência e Tecnologia within the Project Scope: UID/CEC/00319/2013. This work is financed by the ERDF - European Regional Development Fund through the Operational Programme for Competitiveness and Internationalisation - COMPETE 2020 Programme, and by National Funds through the Portuguese funding agency, FCT Fundação para a Ciência e a Tecnologia, within project SAICTPAC/0004/2015- POCI- 01-0145-FEDER-016434. Mr. Tiago Sousa is supported by the doctoral scholarship SFRH/BD/134353/2017 granted by the Portuguese FCT agency.

\section{REFERENCES}

[1] T. Soeiro, T. Friedli, J. W. Kolar, "Three-Phase High Power Factor Mains Interface Concepts for Electric Vehicle Battery Charging Systems," IEEE APEC Applied Power Electronics Conference and Exposition, pp.2603-2610, Feb. 2012.

[2] Bhim Singh, Brij N. Singh, Ambrish Chandra, Kamal Al-Haddad, Ashish Pandey, Dwarka P. Kothari, "A Review of Single-Phase Improved Power Quality AC-DC Converters," IEEE Trans. Ind. Electron., vol.50, no.5, pp.962-981, Oct. 2003.

[3] Oscar García, José A. Cobos, Roberto Pietro, Pedro Alou, Javier Uceda, "Single Phase Power Factor Correction: A Survey," IEEE Trans. Power Electron., vol.18, no.3, pp.749-755, May 2003.

[4] Fernando Beltrame, Leandro Roggia, Luciano Schuch, José Renes Pinheiro, "A Comparison of High Power Single-Phase Power Factor Correction Pre-Regulators," IEEE ICIT Industrial Technology, pp.625630, Mar. 2010.

[5] Vítor Monteiro, Andrés A. Nogueiras Meléndez, Carlos Couto, João L. Afonso, "Model Predictive Current Control of a Proposed Single-Switch Three-Level Active Rectifier Applied to EV Battery Chargers," IEEE IECON Industrial Electronics Conference, Florence Italy, pp.1365-1370, Oct. 2016.

[6] Xueshan Liu, Jianping Xu, Zhangyong Chen, Nan Wang, "SingleInductor Dual-Output Buck-Boost Power Factor Correction Converter," IEEE Trans. Ind. Electron., vol.62, no.2, pp.943-952, Feb. 2015.

[7] Xiaogao Xie, Chen Zhao, Qiang Lu, Shirong Liu, "A Novel Integrated Buck-Flyback Nonisolated PFC Converter With High Power Factor," IEEE Trans. Ind. Electron., vol.60, no.12, pp.5603-5612, Dec. 2013.

[8] Johann W. Kolar, Thomas Friedli, "The Essence of Three-Phase PFC Rectifier Systems-Part I," IEEE Trans. Power Electron., vol.28, no.1, pp.176-198, Jan. 2013

[9] Thomas Friedli, Michael Hartmann, Johann W. Kolar, "The Essence of Three-Phase PFC Rectifier Systems-Part II," IEEE Trans. Power Electron., vol.29, no.2, pp.543-560, Feb. 2014.

[10] André De Bastiani Lange, Thiago Batista Soeiro, Márcio Silveira Ortmann, Marcelo Lobo Heldwein, "Three-Level Single-Phase Bridgeless PFC Rectifiers," IEEE Trans. Power Electron., vol.30, no.6, pp.2935-2949, June 2015.

[11] Laszlo Huber, Yungtaek Jang, Milan Jovanovic, "Performance
Evaluation of Bridgeless PFC Boost Rectifier," IEEE Trans. Power Electron., vol.23, no.3, pp.1381-1390, May 2008.

[12] Roberto Martinez, Prasad N. Enjeti, "A High-Performance Single-phase Rectifier with Input Power Factor Correction," IEEE Trans. Power Electron., vol.11, no.2, pp.311-317, Mar. 1996.

[13] Jee-Woo Lim, Bong-Hwan Kwon, "A Power-Factor Controller for Single-Phase PWM Rectifiers," IEEE Trans. Ind. Electron., vol.46, no.5, pp.1035-1037, Oct. 1999.

[14] Serkan Dusmez, Shamim Choudhury, Manish Bhardwaj, Bilal Akin, "A Modified Dual-Output Interleaved PFC Converter Using Single Negative Rail Current Sense for Server Power Systems," IEEE Trans. Power Electron., vol.29, no.10, pp.5116-5123, Oct. 2014.

[15] Vítor Monteiro, Bruno Exposto, J. G. Pinto, J. C. Aparício Fernandes, Luís F. C. Monteiro, João L. Afonso, "A Novel Architecture of a Bidirectional Bridgeless Interleaved Converter for EV Battery Chargers," IEEE ISIE International Symposium on Industrial Electronics, Rio de Janeiro Brazil, pp.204-209, June 2015.

[16] Pablo Acuña, Luis Morán, Marco Rivera, Juan Dixon, José Rodriguez, "Improved Active Power Filter Performance for Renewable Power Generation Systems," IEEE Trans. Power Electron., vol.29, no.2, pp.687-6945, Feb. 2014.

[17] Leonardo Augusto Serpa, "Current Control Strategies for Multilevel Grid Connected Inverters," PhD Thesis, Swiss Federal Institute of Technology, Zurich, 2007.

[18] Marian P. Kazmierkowski, Luigi Malesani, "Current Control Techniques for Three-Phase Voltage-Source PWM Converters: A Survey," IEEE Trans. Ind. Electron., vol.45, no.5, pp.691-703, Oct. 1998.

[19] Vítor Monteiro, J. G. Pinto, Bruno Exposto, João L. Afonso, "Comprehensive Comparison of a Current-Source and a Voltage-Source Converter for Three-Phase EV Fast Battery Chargers," CPE International Conference on Compatibility and Power Electronics, Lisboa Portugal, pp.173-178, June 2015.

[20] Patricio Cortés, Marian P. Kazmierkowski, Ralph M. Kennel, Daniel E. Quevedo, José Rodríguez, "Predictive Control in Power Electronics and Drives," IEEE Trans. Ind. Electron., vol.55, no.12, pp.4312-4324, Dec. 2008.

[21] P. Zavala, M. Rivera, S. Kouro, J. Rodriguez, B. Wu, V. Yaramasu, C. Baier, J. Munoz, J. Espinoza, P. Melin, "Predictive Control of a Current Source Rectifier with Imposed Sinusoidal Input Currents," IEEE IECON Industrial Electronics Society, Vienna Austria, pp. 5842-5847, Nov. 2013.

[22] Pericle Zanchetta, Patricio Cortes, Marcelo Perez, Jose Rodriguez, Cesar Silva, "Finite States Model Predictive Control for Shunt Active Filters," IEEE IECON Industrial Electronics Conference, pp.581-586, Nov. 2011.

[23] Patricio Cortés, Gabriel Ortiz, Juan I. Yuz, José Rodríguez, Sergio Vazquez, Leopoldo G. Franquelo, "Model Predictive Control of an Inverter With Output LC Filter for UPS Applications,” IEEE Trans. Ind. Electron., vol.56, no.6, pp.1875-1883, June 2009.

[24] Luís Guilherme Barbosa Rolim, Diogo Rodrigues Costa, Maurício Aredes, "Analysis and Software Implementation of a Robust Synchronizing PLL Circuit Based on the pq Theory," IEEE Trans. Ind. Electron., vol.53, no.6, pp.1919-1926, Dec. 2006

[25] Bin Yu, Liuchen Chang, "Improved Predictive Current Controlled PWM for Single-Phase Grid-Connected Voltage Source Inverters,” IEEE PESC Power Electronics Specialists, pp.231-236, June 2005.

[26] José Rodríguez, Jorge Pontt, César A. Silva, Pablo Correa, Pablo Lezana, Patricio Cortés, Ulrich Ammann, "Predictive Current Control of a Voltage Source Inverter," IEEE Trans. Ind. Electron., vol.54, no.1, pp.495-503, Feb. 2007.

[27] Marcos G. Judewicz, Sergio Alejandro González, Noelia I. Echeverría, Jonatan Roberto Fischer, Daniel O. Carrica, "Generalized Predictive Current Control (GPCC) for Grid-Tie Three-Phase Inverters," IEEE Trans. Ind. Electron., vol.63, no.7, pp.4475-4484, July 2016.

[28] Patricio Cortes, Jose Rodriguez, Cesar Silva, Alexis Flores, "Delay Compensation inModel Predictive Current Control of a Three-Phase Inverter," IEEE Trans. Ind. Electron., vol.59, no.2, pp.1323-1325, Feb. 2012. 